\title{
The Influence of Energy of Consciousness Healing Treatment on Low Bioavailable Resveratrol in Male Sprague Dawley Rats
}

\author{
Alice Branton ${ }^{1}$, Snehasis Jana ${ }^{2, *}$ \\ ${ }^{1}$ Trivedi Global, Inc., Henderson, Nevada, USA \\ ${ }^{2}$ Trivedi Science Research Laboratory Pvt. Ltd., Bhopal, Madhya Pradesh, India
}

Email address:

publication@trivedieffect.com (S. Jana)

${ }^{*}$ Corresponding author

\section{To cite this article:}

Alice Branton, Snehasis Jana .The Influence of Energy of Consciousness Healing Treatment on Low Bioavailable Resveratrol in Male Sprague Dawley Rats. International Journal of Clinical and Developmental Anatomy. Vol. 3, No. 3, 2017, pp. 9-15. doi: $10.11648 /$ j.ijcda.20170303.11

Received: May 20, 2017; Accepted: June 14, 2017; Published: July 14, 2017

\begin{abstract}
Resveratrol is a natural dietary antioxidant polyphenol that believed to be effective in improving overall health. The biological activity of resveratrol is limited by its poor absorption and first-pass metabolism that lead to have very low plasma concentrations following oral administration. Therefore, the present study was performed to determine the effects of The Trivedi Effect ${ }^{\mathbb{B}}$-Energy of Consciousness Healing Treatment by a renowned Biofield Energy Healer, Alice Branton on resveratrol and rats through the measurement of plasma concentrations after oral administration of resveratrol. The test item, resveratrol was divided into two parts. One part was denoted as the control, while the other part was defined as the Biofield Energy Treated sample. Additionally, one group of animals also received Biofield Energy Treatment under similar conditions. Resveratrol oral formulations were administrated by oral gavage at a dose of $150 \mathrm{mg} / \mathrm{kg}$ in groups viz. G1 (untreated resveratrol), G2 (Biofield Treated resveratrol) and G3 (Biofield Treated animals received untreated resveratrol) group. The results showed that resveratrol had a very low oral plasma exposure of $91.71 \mathrm{ng} / \mathrm{mL}$ in control group. The Biofield Treatment significantly enhanced the relative oral exposure $\left(\mathrm{AUC}_{0-\mathrm{t}}\right)$ of resveratrol by $23.35 \%$ in $\mathrm{G} 2$ group compared to the control group. The Biofield Treatment also improved plasma peak concentration $\left(\mathrm{C}_{\max }\right)$ of resveratrol by $125 \%$ and $28.5 \%$ in $\mathrm{G} 2$ and G3 groups, respectively compared with the control group. Plasma concentrations of resveratrol in G1 was declined with a rapid elimination half-life ( $T_{1 / 2}, 1.48$ hours), followed by sudden increases in plasma concentrations 12 to 24 hours after the test item administration. These plasma concentrations resulted in a significant prolongation of the terminal elimination half-life of resveratrol. The oral elimination $\mathrm{T}_{1 / 2}$ of resveratrol in G2 and G3 were 4.67 and 9.0 hours, respectively as compared to the G1. The apparent oral plasma clearance of resveratrol decreased significantly by $54 \%$, and $17.5 \%$ in G2 group and G3 group, respectively as compared to the control group. The mean residence time ( $\mathrm{MRT}_{\text {last }}$ ) of resveratrol significantly increased in G2 group (6.45 hours) and G3 group ( 7.70 hours), as compared to the control group. These data demonstrates greater bioavailability and total plasma level of resveratrol in rats which might be translated into better in vivo biological activity. Hence, The Trivedi Effect ${ }^{\mathbb{B}}$-Energy of Consciousness Healing Treatment could be considered as an innovative strategy which opens new avenues to overcome poorly absorbed nutraceuticals/pharmaceuticals and can also improve the therapeutic performance of orally active molecules.
\end{abstract}

Keywords: Resveratrol, Biofield Energy Healing Treatment, Pharmacokinetics, Bioavailability, LC-MS/MS, Rat

\section{Introduction}

Resveratrol (3,5,4'-Trihydroxystilbene), a natural polyphenol found in some plants and fruits, has been used as traditional medicine for over 2000 years against a wide range of biological activities. Some commonly used plants of human diets that contain a high concentration of resveratrol are blueberries (Vaccinium spp.), blackberries (Morus spp.), 
and peanuts (Arachis hypogaea) [1, 2]. In addition, red wine made from grapes (Vitaceae) are considered as rich source of resveratrol in the Mediterranean diet particularly from skin, seeds, petioles, and woody parts [3]. Due to this reason, most parts of the grape plants are used for red wine production during concentration, which made it richer source of resveratrol as compared with the white wine $[4,5]$. Due to its significant natural biological importance such as strong antoxidative potential, antitumor, cardiovascular, etc. properties resveratrol can be consumed via natural products or in the form of nutraceuticals. Among these wide pharmacological properties, some major extensively studies have been reported in humans and animal models, both in vitro and in vivo [11-13] as an anticancer agent, a platelet antiaggregation agent, and an antioxidant, as well as its antiaging, anti-fertility, anti-inflammatory, anti-allergenic, and so forth activities [6-10]. Due to its unique physiochemical property, its mechanism of action and issue of bioavailability play an important role for its biological action. Literature suggested that resveratrol bioavailability was determined by its rapid elimination via metabolism pathways that affect its absorption process. Besides, the low oral bioavailability of resveratrol (less than 1\%) is due to the rapid first-pass metabolism; glucuronide and sulfate conjugates, which are the major metabolites reported in plasma [14]. Clinical studies data of resveratrol pharmacokinetic parameters led to a questions concerning whether high oral doses of resveratrol can achieve sufficient plasma concentration of resveratrol required to achieve the desirable activities like chemopreventive action [15]. Various traditional techniques have been reported in order to improve the bioavailability of compounds such as the use of co-solvents, amorphous forms, use of precipitation inhibitors, $\mathrm{pH}$ alteration, addition of surfactants, chemical modification of drug, etc. In addition, some methods such as modification in dielectric constant of solvent, hydrotropy, micronization, application of ultrasonic waves, etc. were reported [16]. Authors have used complementary approach i.e. Biofield Energy Healing Treatment to resveratrol and animals in order to evaluate the alteration in bioavailability after treatment.

The human Biofield Energy, a subtle electromagnetic energy around the human body has significant capacity for various clinical benefits [17]. Various clinical reports suggested the significant use of energy medicine and its healing capacity, which is well demarcated by National Center for Complementary and Integrative Health (NCCIH) in order to promote wellness [18]. Biofield Energy Treatment leads to receive the energy by the object and respond in a useful way, while The Trivedi Effect ${ }^{\circledR}$ has been reported with the significant discovery in both living organisms and nonliving materials. The Trivedi Effect ${ }^{\circledR}$ has been described with significant transformation in the physicochemical properties of metals, chemicals, ceramics and polymers [1822], improved agricultural crops overall productivity, yield and quality by several folds [23-24], altered antimicrobial characteristics of pathogenic microbes at genetic level [2527], improved activity of nutraceutical compounds [28, 29], livestock [30], and many more.

Recently, it has been reported in the literature that The Trivedi Effect ${ }^{\circledR}$ has the significant capability to alter the physicochemical and thermal properties of various pharmaceuticals, nutraceuticals, and organic compounds through possible intervention of neutrinos [31, 28]. The Trivedi Effect ${ }^{\circledR}$-Consciousness Energy Healing Treatment would be a useful approach for the enhancement of the bioavailability of pharmaceuticals and nutraceuticals. The present study was planned to evaluate The Trivedi Effect ${ }^{\circledR}$ Consciousness Energy Healing Treatment on the test item (resveratrol), and test system (rat) through the estimation of resveratrol in plasma concentration after a single dose of oral administration of resveratrol in rat.

\section{Materials and Methods}

\subsection{Chemicals and Reagents}

Resveratrol chloride and telmisartan were purchased from TCI, Japan and Sigma (St. Louis, MO, USA), respectively. The reagents used for sample preparation and bioanalysis included acetonitrile (HPLC Grade, Merck), methanol (HPLC Grade, Merck), water (Milli-Q), and formic acid (LCMS Grade, Fluka). USP grade nitrogen was used as the curtain gas and collision gas for LC-MS/MS were supplied from air compressor (Anesta Iwata, Japan), polypropylene tubes (Tarsons, India), class-A, measuring cylinders and volumetric flasks (Borosil, Germany) and membrane filters, $0.22 \mu \mathrm{m}$ and $0.45 \mu \mathrm{m}$ (Millipore) were used during the study. All other reagents and solvents were of analytical grade available from India.

\subsection{Energy of Consciousness Treatment Strategies}

The test item, resveratrol was divided into two parts. One part was considered as the control group, while the other part was defined as the Biofield Energy Treated test group. The test item in Biofield Treated group was subjected to The Trivedi Effect ${ }^{\circledR}$ - Energy of Consciousness Healing Treatment by a renowned Biofield Energy Healer, Alice Branton, USA. Additionally, one group of animals also received the Biofield Energy Treatment per se by the same Biofield Energy Healer under similar experimental conditions. This Biofield Treatment was provided for approximately 5 minutes through the Biofield Energy Healer's unique Energy Transmission process (The Trivedi Effect ${ }^{\circledR}$ ), administered to the test sample and animals. Similarly, the control test sample was subjected to "sham" healer for 5 minutes, under similar laboratory conditions without having any awareness about the Biofield Energy Treatment. Further, the Biofield Energy Treated and untreated test items were kept in similar sealed conditions and used for the study as per design.

\subsection{In Vivo Pharmacokinetics Study}

\subsubsection{Animals}

Male Sprague-Dawley (SD) rats (body weight 230 - 270 gm) were procured from Liveon Biosciences, Bangalore, 
India. Animals were housed in polycarbonate cage. For maintenance of animals, standard conditions such as temperature and humidity were maintained at $22 \pm 3^{\circ} \mathrm{C}$ and $40-70 \%$, respectively and illumination was controlled to give a sequence of 12 hours light and 12 hours dark cycle. The temperature and humidity were recorded by auto-controlled data logger system. All the animals were provided laboratory rodent diet (Vetcare India Pvt. Ltd, Bengaluru). Reverse osmosis water treated with ultraviolet light was provided ad libitum. The experiments using animals in this investigation were performed in accordance with the guidelines provided by the Committee for the Purpose of Control and Supervision of Experiments on Animals (CPCSEA) as published in The Gazette of India, January 7, 2010 and protocol approved by the Institutional (GVK Bio) Animal Ethics Committee (IAEC approval number: BA-011).

\subsubsection{Experimental Design}

Rats were divided into three groups $(\mathrm{n}=3)$ : group 1 (Gr. 1) - per oral (p.o.) dosing of untreated resveratrol, group 2 (Gr. 2) - per oral (p.o.) dosing of Biofield Energy Treated resveratrol and group 3 (Gr. 3) - per oral (p.o.) dosing of untreated resveratrol in the Biofield Energy Treated animals. All animals were received per oral dose at $100 \mathrm{mg} / \mathrm{kg}$ of resveratrol solution formulation. The dose $(150 \mathrm{mg} / \mathrm{kg})$ of the test item was chosen based on the preliminary experiments performed in the laboratory and observed the quantifiable concentration of this analyte in rat plasma.

\subsection{Formulation Preparation}

The solution formulations of the test item was prepared in $40 \% w / v 2$-Hydroxypropyl- $\beta$-cyclodextrin in distilled water. All formulations were prepared freshly prior to dosing. The dose volume for per oral route was $10 \mathrm{~mL} / \mathrm{kg}$.

\subsection{Pharmacokinetic Studies}

The solution of resveratrol chloride formulations were freshly prepared for per oral dosing. All rats were fasted overnight and the fasting continued up to 4 hours post dosing with free access to drinking water. The oral test formulation was administered at $150 \mathrm{mg} / \mathrm{kg}$ dose through oral gavage using an $18 \mathrm{G}$ stainless steel intubation cannula. The dosing volume administered was $10 \mathrm{~mL} / \mathrm{kg}$. Blood samples $(\sim 120$ $\mu \mathrm{L})$ were collected from the jugular vein catheter of three rats from each group at each time point [pre-dose, 0.25, 0.5, $1,2,4,8,12$, and 24 hours (p.o.)]. Samples were collected into labeled micro centrifuge tubes, containing 20\% $\mathrm{w} / \mathrm{v}$ $\mathrm{K}_{2}$ EDTA as an anticoagulant. Plasma samples were separated from the blood by centrifugation at $2500 \mathrm{~g}$ for $10 \mathrm{~min}$ at $4 \pm$ $2{ }^{\circ} \mathrm{C}$ and stored below $-40^{\circ} \mathrm{C}$ (Thermo Scientific, USA) deep freezer until bioanalysis.

\subsection{LC-MS/MS Analysis}

LC-MS/MS analysis of rat plasma samples was performed using API 4500 Applied Biosystem-SCIEX (Concord, Ontario, Canada) triple quadruple mass analyzer system with the Turbo Ion Spray interface connected to a Shimadzu UFLC system (Shimadzu Corp., Japan). The optimum operating parameters were determined by electro spray ionization (ESI) interface in negative ion mode. A generic mass spectrometry parameters of the analyte were developed and used for the analysis. These parameters were the declustering potential range (-80), collision energy range ($34)$, collision cell exit potential range $(-8)$, curtain gas (30 arbitrary units), collisionally activated dissociation gas (10), ionspray voltage $(-4500 \mathrm{~V})$, source temperature $\left(550^{\circ} \mathrm{C}\right)$, and ion source/nebulizer gas 1 and gas 2 (50 and 55, respectively arbitrary units each). Interface heaters were kept on for the analyte. The analyte was detected by negative Turbo Ion Spray in the multiple reaction monitoring mode (MRM) mode using predetermined parent/product mass transition ion pairs. The parameters of the selected MRM monitoring transitions for the $[\mathrm{M}-\mathrm{H}]^{-}$precursor ion to selected product ion $(\mathrm{m} / \mathrm{z})$ were optimized with 226.90/142.90 (resveratrol), and 515.30/286.70 (telmisartan as an internal standard. The whole system was controlled by Analyst ${ }^{\mathbb{B}}$ software version 1.6.3 (Applied Biosystem/MDS SCIEX, Concord, Canada). Stock solutions of resveratrol and telmisartan (internal standard, IS) were prepared in methanol at approximately $9.999 \mathrm{mg} / \mathrm{mL}$ and $0.98 \mathrm{mg} / \mathrm{mL}$, respectively and subsequently diluted which were used for the bioanalysis.

The extraction procedure for plasma samples or the spiked into plasma calibration standards were identical. A $50 \mu \mathrm{L}$ sample of either study sample or spiked calibration standard was added to individual pre-labeled micro-centrifuge tubes. A $50 \mu \mathrm{L}$ sample of either study sample or spiked calibration standard/quality control samples were added to individual wells of 96 well plate with $500 \mu \mathrm{L}$ capacity. $200 \mu \mathrm{L}$ of internal standard (IS) prepared in acetonitrile (ACN) was added to the samples in deep well plate except for blank, where $200 \mu \mathrm{L}$ of ACN was added and vortexed for 5 minutes. Samples were centrifuged for 10 minutes at a speed of $4000 \mathrm{rpm}$ (3220 g) at $4{ }^{\circ} \mathrm{C}$. Following centrifugation, $120 \mu \mathrm{L}$ of supernatant was transferred into $1000 \mu \mathrm{L}$ capacity deep well plate and mixed with $120 \mu \mathrm{L}$ of methanol: water, 50:50 $\nu / v$. The plate was kept in the auto-sampler for the LC-MS/MS analysis.

A Shimadzu LC-20AD LC system (Shimadzu Corp., Japan) was connected to a SIL -20 AC HT auto-sampler (Shimadzu Corp., Japan). The supernatant was injected $(15 \mu \mathrm{L})$ onto a $50 \times 4.6 \mathrm{~mm}(3.5 \mu \mathrm{m})$ Waters, X-Bridge, C18 HPLC column (Waters, Massachusetts, Ireland). Analytes were eluted using a gradient elution program with a mobile phase consists of $10 \mathrm{mM}$ ammonium acetate in water (pump A) with methanol (pump B) at a flow rate of $1.0 \mathrm{~mL} / \mathrm{min}$. The column temperature was at $40^{\circ} \mathrm{C}$ and the sample temperature was at $15^{\circ} \mathrm{C}$. The following linear gradient was employed for the separation: $95 \% \mathrm{~A}$ for 0.01 $\mathrm{min}, 60 \% \mathrm{~A}$ at $0.5 \mathrm{~min}, 40 \% \mathrm{~A}$ at $1.0 \mathrm{~min}, 25 \% \mathrm{~A}$ at 2.0 $\mathrm{min}$, and hold to $3.2 \mathrm{~min}, 95 \% \mathrm{~A}$ at $3.3 \mathrm{~min}$ and hold to $5.0 \mathrm{~min}$. The resveratrol and telmisartan elution times were approximately 1.69 and $2.22 \mathrm{~min}$, respectively. Peak integration, regression and calculation of analytes concentration were computed using Analyst Classic 
(Version 1.6.3) software. The calibration curve was performed by linear curve fit of the peak area ratio (analyte/internal standard) as a function of the concentration in the respective matrix. A weighting of $1 / \mathrm{x}^{2}$ (where $\mathrm{x}$ is the concentration of a given calibration standard level) was found to be optimal. The lower limit of quantification (LLOQ) in rat plasma was $1.02 \mathrm{ng} / \mathrm{mL}$ for resveratrol. Analysis of resveratrol in plasma (1.04 $1038.96 \mathrm{ng} / \mathrm{mL}$ ) showed a repeatability (relative standard deviation-RSD $\%$ ) of $1.5 \%$ to $8.47 \%$ and accuracy of $100.18 \%$ to $108.81 \%$.

\subsection{Pharmacokinetic Analysis}

The pharmacokinetic parameters of resveratrol were obtained by noncompartmental analysis module in Phoenix WinNonlin $^{\circledR}$ (Version 7.0) (Pharsight, Mountain View, CA). The areas under the concentration time curve $\left(\mathrm{AUC}_{0-\mathrm{t}}\right.$ and $\left.\mathrm{AUC}_{0-\infty}\right)$ were calculated by linear trapezoidal rule. The terminal elimination rate constant $\left(\mathrm{k}_{\mathrm{el}}\right)$ was determined by regression analysis of the linear terminal portion of the $\log$ plasma concentration-time curve. The terminal half-life $\left(\mathrm{T}_{1 / 2}\right)$

was estimated as $0.693 / \mathrm{k}_{\mathrm{el}}$; the apparent oral clearance $(\mathrm{CL} / F)$ were calculated for per oral dose divided by AUC, respectively. Peak resveratrol concentrations $\left(\mathrm{C}_{\max }\right)$ and the times when they occurred $\left(t_{\max }\right)$ were derived directly from the data. The relative oral bioavailability $(\mathrm{Fr})$ was estimated by $\mathrm{AUC}_{\text {treated }} / \mathrm{AUC}_{\text {control }}$.

\subsection{Statistical Analysis}

All mean values are presented with their standard deviation (mean \pm S.D.). Data were analyzed for statistically significant differences using analysis of variance followed by the two-sided unpaired Student's $t$ test. Differences were considered to be significant at a level of $p<0.05$.

\section{Results and Discussions}

The mean pharmacokinetic parameters and profiles of resveratrol in the rat plasma after a single oral dose of administration of solution formulations in three different groups are summarized in Table 1 and Figure 1, respectively.

Table 1. Pharmacokinetic parameters of resveratrol after p.o. administration at $100 \mathrm{mg} / \mathrm{kg}$ body weight to Sprague Dawley male rats.

\begin{tabular}{llll}
\hline Parameter & Gr. 1 (Untreated Resveratrol) & Gr. 2 (Biofield Treated Resveratrol) & $\begin{array}{l}\text { Gr. 3 (Biofield Treated Rats + } \\
\text { Untreated Resveratrol) }\end{array}$ \\
\hline $\mathrm{C}_{\max }(\mathrm{ng} / \mathrm{mL})$ & 43.30 & 97.37 & 55.64 \\
$\mathrm{~T}_{\max }($ hours) & 0.50 & 0.42 & 0.25 \\
$\mathrm{AUC}_{0-\mathrm{t}}(\mathrm{ng} / \mathrm{mL}$ (hours) & 91.71 & 113.13 & 76.75 \\
$\mathrm{~T}_{\text {half }}$ (hours) & 1.48 & 7.96 & 10.03 \\
$\mathrm{MRT}_{\text {last }}$ (hours) & 1.61 & 6.45 & 7.7 \\
$\mathrm{CL} / \mathrm{F}(\mathrm{L} /$ hours/kg) & 8.06 & 3.64 & 6.65 \\
$\mathrm{Vd} / \mathrm{F}(\mathrm{L} / \mathrm{kg})$ & 1724.75 & 1234.55 & 2328.4 \\
$\mathrm{~K}_{\mathrm{el}}\left(\right.$ hour $\left.^{-1}\right)$ & 0.1 & 0.09 & 0.1 \\
$\mathrm{~K}_{\mathrm{a}}\left(\right.$ hour $\left.^{-1}\right)$ & 0.4 & 0.31 & 0.21 \\
$\mathrm{MAT}($ hour) & 7.09 & 3.63 & 6 \\
$\%$ Change in Fr & & 23.35 & 16.28 \\
\hline
\end{tabular}

The data are expressed as mean values. AUC: area under the plasma concentration-time curve from 0 hours to infinity; $\mathrm{CL} / F$ : apparent oral plasma clearance; $\mathrm{Vd} / F$ : apparent volume of distribution; $\mathrm{C}_{\max }$ : peak concentration; $\mathrm{T}_{\max }$ : time to reach peak concentration; $\mathrm{T}_{1 / 2}$ : terminal half-life; $\mathrm{K}_{\mathrm{el}}$ : absorption rate constant; $\mathrm{K}_{\mathrm{a}}$ : absorption rate constant, MRT: mean residence time; MAT: mean absorption time; p.o.: per oral; Fr: Relative oral Bioavailability.

The $\mathrm{C}_{\max }$ of resveratrol formulation in control group was $43.3 \mathrm{ng} / \mathrm{mL}$ after 0.50 hours, whereas it was $97.37 \mathrm{ng} / \mathrm{mL}$ and $55.64 \mathrm{ng} / \mathrm{mL}$ for the resveratrol formulation after 0.42 hours and 0.25 hours, in G2 and G3 group, respectively. The results showed that resveratrol had a very low oral exposure $\left(\mathrm{AUC}_{0-\mathrm{t}}\right)$ of $91.71 \mathrm{ng} / \mathrm{mL}$ in control (untreated) group. After the Biofield Energy Treatment by a renowned Biofield Energy Healer, Alice Branton, the relative oral exposure $\left(\mathrm{AUC}_{0-\mathrm{t}}\right)$ of resveratrol was enhanced significantly by $23.36 \%$ in G2 group, as compared to the control group. The Biofield Energy Treatment also improved plasma peak concentration $\left(\mathrm{C}_{\max }\right)$ of resveratrol by $125 \%$ and $28.5 \%$ in G2 and G3 groups, respectively as compared to the control group.
After oral administration, plasma concentrations of resveratrol in control group (G1) declined with a rapid elimination half-life $\left(\mathrm{T}_{1 / 2}, 1.48\right.$ hours $)$, followed by sudden increases in plasma concentrations at 12 hours and 24 hours after the test item administration (Figure 1). These plasma concentrations resulted in a significant prolongation of the terminal elimination half-life of resveratrol. The oral elimination half-life $\left(\mathrm{T}_{1 / 2}\right)$ of resveratrol in the Biofield Energy Treatment group (G2) and Biofield Treated rat group (G3) were 4.67 and 9.0 hours, reactively as compared to the control group (G1). The apparent oral plasma clearance of resveratrol was decreased significantly $(p<0.05)$ by $54.58 \%$, and $17.5 \%$ in G2 group and G3 group, respectively as compared to the control group. The mean residence time $\left(\mathrm{MRT}_{\text {last }}\right)$ of resveratrol was significantly increased in G2 group $(6.45$ hours) and G3 group (7.70 hours), as compared to the control group. These data demonstrates greater bioavailability and total plasma level of resveratrol compound in rats which might be translated into better in vivo biological activity of resveratrol. 


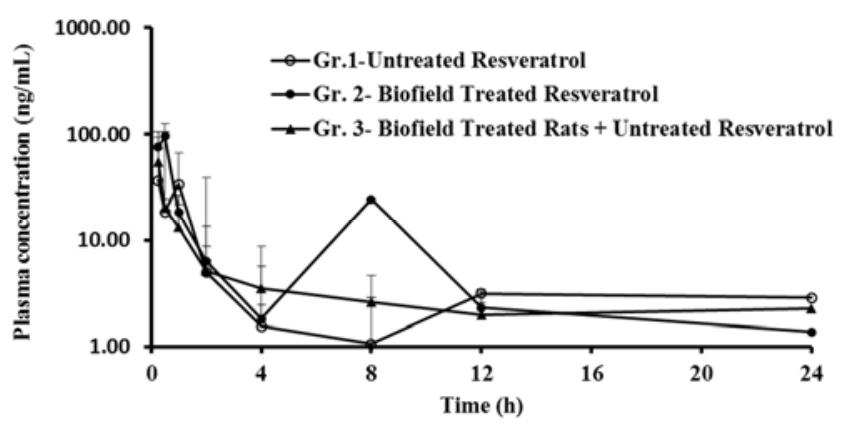

Figure 1. Mean plasma concentration-time profiles of resveratrol after per oral (p.o.) administration (100 mg/kg) to Sprague Dawley male rats. The data are expressed as mean $\pm S . D(n=3)$.

The results indicated that the Biofield Energy Treated resveratrol and animals per se significantly increased the rate and extent of oral absorption of resveratrol. The enhanced absorption efficiency may be explained as follows: (1) the huge specific surface area of the resveratrol formulation, (2) the stability of the resveratrol formulation in the gastrointestinal tract, and (3) delayed resveratrol metabolism pathways. The significant improvement of relative oral bioavailability of resveratrol in Biofield Energy Treated group might be translated into increased pharmacological effects in various disease conditions.

Resveratrol is a natural polyphenol with a stilbene structure containing two phenolic rings bonded together by a double styrene bond that results in 3,5,4'-trihydroxystilbene (molecular weight $228.25 \mathrm{~g} / \mathrm{mol}$ ) [32]. The isometric cis- and trans-forms of resveratrol is due to the double bond present in the structure. The accumulation of resveratrol in plants is produced by a mechanism of resistance to parasites and other adverse conditions such as chemical substances, fungal infection, UV radiation, and in general, stressful factors for the plant [33-35]. Literature data suggest that most of the plant species produced resveratrol in response to stressful conditions [36] and was found in most of the fruits of human diets [37, 38]. Cis- and trans-isomers co-occur in plants and in wine, while grape extract lacks the cis-resveratrol form [39]. However, more predominant and stable natural form of resveratrol is trans-isomer. Resveratrol has wide biological importance such as reduction of cardiovascular risk [40], minimize the incidence of arterial hypertension, heart failure and ischemic cardiac disease [41, 42], improve insulin sensitivity by minimizing the plasma glycemia levels, and obesity in rodent models [43]. Due to its different physicochemical properties such as molecular weight, number of hydrogen bond donor and acceptor, rotatable bond, clogP, and polar surface area, resveratrol has poor biomembrane permeability. The poor oral bioavailability [14] considerably less than $1 \%$ would attribute to different the metabolic issue [44], such as very short half-life in rat liver microsomes. Furthermore, poor oral bioavailability is due to the first-pass metabolism in intestine [45, 46], while increased dose and repeated dose escalation would not affect the bioavailibity. Therefore, this study was carried out to evaluate the pharmacokinetic properties of resveratrol using the novel technique known as The Trivedi Effect ${ }^{\circledR}$-Energy of Consciousness Healing Treatment on resveratrol and animals. To the authors' knowledge, this is the first report to demonstrate the effects of Biofield Energy Treatment on resveratrol pharmacokinetics in rats after a single dose of oral administration. Pharmacokinetic profiles of resveratrol in three different groups were compared in male rats following a single oral (gavage) dose. The study results demonstrated that markedly higher $\mathrm{C}_{\max }$ values for the Biofield Energy Treated groups (G2 and G3) were observed as compared to untreated group (G1). The relative oral bioavailability of Biofield Treated group (G2) was significantly higher than the oral bioavailability of control group. It also found that oral plasma clearance $(\mathrm{CL} / \mathrm{F})$ and $\mathrm{T}_{1 / 2}$ values of resveratrol were significantly altered in the Biofield Treated groups. Lower clearance values in $\mathrm{G} 2$ group was correlated well for the higher plasma exposure $\left(\mathrm{AUC}_{0-\mathrm{t}}\right)$ to resveratrol in comparison with the untreated group. The results clearly demonstrate the significant effect of Biofield Energy Treatment with respect to the increased oral exposure of resveratrol.

\section{Conclusions}

The Trivedi Effect ${ }^{\circledR}$-Energy of Consciousness Healing Treatment significantly enhanced the relative oral exposure $\left(\mathrm{AUC}_{0-\mathrm{t}}\right)$ of resveratrol by $23.35 \%$ in the $\mathrm{G} 2$ group compared to the control group. The Biofield Energy Treatment also improved the plasma peak concentration $\left(\mathrm{C}_{\max }\right)$ of resveratrol by $125 \%$ and $28.5 \%$ in the $\mathrm{G} 2$ and $\mathrm{G} 3$ group, respectively as compared to the control group. The oral elimination half-life $\left(\mathrm{T}_{1 / 2}\right)$ of resveratrol in the Biofield Energy Treatment group (G2) and Biofield Treated animal group per se (G3) were 4.67 and 9.0 hours, respectively as compared to the control group (G1). The apparent oral plasma clearance of resveratrol was decreased significantly $(p<0.05)$ by $54 \%$ and $17.5 \%$ in the G2 and G3 group, respectively as compared to the control group. The mean residence time $\left(\mathrm{MRT}_{\text {last }}\right)$ of resveratrol was significantly increased in G2 group (6.45 hours) and G3 group (7.70 hours), as compared to the control group. These data demonstrates greater bioavailability and total plasma level of resveratrol observed in rats which might be translated into better in vivo biological activity of resveratrol. An improvement of oral resveratrol bioavailability might be due to the alteration of physicochemical properties and thermal properties by Biofield Energy Treatment. The Energy of Consciousness Healing Treatment is shown here as an innovative strategy which opens new avenues to overcome poorly absorbed drug/nutraceuticals/herbal extracts and can also improve the therapeutic performance of orally active molecules. Thereby, the Biofield Energy Treated resveratrol and Biofield Energy Healing Treatment per se showed improved bioavailability, which can significantly prevent or delay the onset of cancer, heart disease, neurodegenerative diseases, metabolic disorders, ischaemic and chemically induced injuries, diabetes, 
pathological inflammation, and viral infection.

\section{Acknowledgements}

Authors are grateful to GVK Bioscience, Trivedi Science, Trivedi Global, Inc., Trivedi Testimonials and Trivedi Master Wellness for their support throughout the work.

\section{References}

[1] Langcake P (1981) Disease resistance of Vitis spp. and the production of the stress metabolites resveratrol, epsilonviniferin, alpha-viniferin and pterostilbene. Physiol Plant Pathol 18: 213-226.

[2] Gambini J, López-Grueso R, Olaso-González G, Inglés M, Abdelazid K, et al. (2013) Resveratrol: distribution, properties and perspectives. Rev Esp Geriatr Gerontol 48: 79-88.

[3] Kraft TE, Parisotto D, Schempp C, Efferth T (2009) Fighting cancer with red wine? Molecular mechanisms of resveratrol. Crit Rev Food Sci Nutr 49: 782-799.

[4] Renaud S, de Lorgeril M (1992) Wine, alcohol, platelets, and the French paradox for coronary heart disease. Lancet 339: 1523-1526.

[5] Jang M, Cai L, Udeani GO, Slowing KV, Thomas CF, Beecher $\mathrm{CW}$, Fong $\mathrm{HH}$, Farnsworth NR, Kinghorn AD, Mehta RG, Moon RC, Pezzuto JM (1997) Cancer Chemopreventive Activity of Resveratrol, a Natural Product Derived from Grapes. Science 275: 218-220.

[6] Aggarwal BB, Bhardwaj A, Aggarwal RS, Seeram NP, Shishodia S, et al. (2004) Role of resveratrol in prevention and therapy of cancer: Preclinical and clinical studies. Anticancer Res 24: 2783-2840.

[7] Delmas D, Aires V, Limagne E, Dutartre P, Mazué F, Ghiringhelli F, Latruffe N (2011) Transport, stability, and biological activity of resveratrol. Ann N Y Acad Sci 1215: 4859.

[8] Marques FZ, Markus MA, Morris BJ (2009) Resveratrol: cellular actions of a potent natural chemical that confers a diversity of health benefits. Int J Biochem Cell Biol 41: 21252128.

[9] Paul S, Rimando AM, Lee HJ, Ji Y, Reddy BS, Suh N (2009) Anti-inflammatory action of pterostilbene is mediated through the p38 mitogen-activated protein kinase pathway in colon cancer cells. Cancer Prev Res 2: 650-657.

[10] Pervaiz S, Holme AL (2009) Resveratrol: its biologic targets and functional activity. Antioxid Redox Signal 11: 2851-2897.

[11] Bishayee A (2009) Cancer prevention and treatment with resveratrol: from rodent studies to clinical trials. Cancer Prev Res 2: 409-418.

[12] De Santi C, Pietrabissa A, Spisni R, Mosca F, Pacifici GM (2000) Sulphation of resveratrol, a natural product present in grapes and wine, in the human liver and duodenum. Xenobiotica 30: 609-617.

[13] Rimando AM, Suh N (2008) Biological/chemopreventive activity of stilbenes and their effect on colon cancer. Planta Med 74: 1635-1643.
[14] Walle T (2011) Bioavailability of resveratrol. Ann N Y Acad Sci 1215: 9-15.

[15] Brown VA, Patel KR, Viskaduraki M, Crowell JA, Perloff M, Booth TD, Vasilinin G, Sen A, Schinas A, Piccirilli G, Brown K, Steward W, Gescher AJ, Brenner DE (2010) Repeat dose study of the cancer chemopreventive agent resveratrol in healthy volunteers: safety, pharmacokinetics and effect on the insulin-like growth factor axis. Cancer Res 70: 9003-9011.

[16] Kansara H, Panola R, Mishra A (2015) Techniques used to Enhance Bioavailability of BCS Class II Drugs: A Review. Int J Drug Dev \& Res 7: 82-93.

[17] Rubik B, Muehsam D, Hammerschlag R, Jain S (2015) Biofield science and healing: history, terminology, and concepts. Glob Adv Health Med 4: 8-14.

[18] Barnes PM, Bloom B, Nahin RL (2008) Complementary and alternative medicine use among adults and children: United States, 2007. Natl Health Stat Report 12: 1-23.

[19] Trivedi MK, Tallapragada RM (2008) A transcendental to changing metal powder characteristics. Met Powder Rep 63: $22-28,31$.

[20] Trivedi MK, Nayak G, Patil S, Tallapragada RM, Latiyal O (2015) Studies of the atomic and crystalline characteristics of ceramic oxide nano powders after bio field treatment. Ind Eng Manage 4: 161.

[21] Trivedi MK, Nayak G, Patil S, Tallapragada RM, Latiyal O, Jana S (2015) Effect of Biofield energy treatment on physical and structural properties of calcium carbide and praseodymium oxide. International Journal of Materials Science and Applications 4: 390-395.

[22] Trivedi MK, Tallapragada RM, Branton A, Trivedi D, Nayak G, Latiyal O, Jana S (2015) Characterization of physical, thermal and structural properties of chromium (VI) oxide powder: Impact of biofield treatment. J Powder Metall Min 4: 128.

[23] Patil SA, Nayak GB, Barve SS, Tembe RP, Khan RR (2012) Impact of biofield treatment on growth and anatomical characteristics of Pogostemon cablin (Benth.). Biotechnology 11: 154-162.

[24] Nayak G, Altekar N (2015) Effect of biofield treatment on plant growth and adaptation. J Environ Health Sci 1: 1-9.

[25] Trivedi MK, Patil S, Shettigar H, Gangwar M, Jana S (2015) Antimicrobial sensitivity pattern of Pseudomonas fluorescens after biofield treatment. J Infect Dis Ther 3: 222.

[26] Trivedi MK, Patil S, Shettigar H, Bairwa K, Jana S (2015) Phenotypic and biotypic characterization of Klebsiella oxytoca: An impact of biofield treatment. J Microb Biochem Technol 7: 203-206.

[27] Trivedi MK, Patil S, Shettigar H, Gangwar M, Jana S (2015) An effect of biofield treatment on multidrug-resistant Burkholderia cepacia: A multihost pathogen. J Trop Dis 3: 167.

[28] Trivedi MK, Branton A, Trivedi D, Nayak G, Balmer AJ, Anagnos D, Kinney JP, Holling JM, Balmer JA, Duprey-Reed LA, Parulkar VR, Panda P, Sethi KK, Jana S (2017) Evaluation of the Energy of Consciousness Healing Treated Withania Somnifera (Ashwagandha) Root Extract Using LCMS, GC-MS, and NMR Spectroscopy, American Journal of Biomedical and Life Sciences 5: 16-25. 
[29] Trivedi MK, Branton A, Trivedi D, Nayak G, Balmer AJ, Anagnos D, Kinney JP, Holling JM, Balmer JA, Duprey-Reed LA, Parulkar VR, Panda P, Sethi KK, Jana S (2017) Evaluation of Physicochemical, Spectral, Thermal and Behavioral Properties of the Biofield Energy Healing Treated Sodium Selenate, Science Journal of Chemistry 5: 12-22.

[30] Trivedi MK, Branton A, Trivedi D, Nayak G, Mondal SC, Jana S (2015) Effect of biofield treated energized water on the growth and health status in chicken (Gallus gallus domesticus). Poult Fish Wildl Sci 3: 140.

[31] Trivedi MK, Mohan TRR (2016) Biofield energy signals, energy transmission and neutrinos. American Journal of Modern Physics 5: 172-176.

[32] Brisdelli F, D’Andrea G, Bozzi A (2009) Resveratrol: a natural polyphenol with multiple chemopreventive properties (Review). Curr Drug Metab 10: 530-546.

[33] Athar M, Back JH, Kopelovich L, Bickers DR, Kim AL (2009) Multiple molecular targets of resveratrol: anticarcinogenic mechanisms. Arch Biochem Biophys 486: 95102.

[34] Athar M, Back JH, Tang X, Kim KH, Kopelovich L, Bickers DR, Kim AL (2007) Resveratrol: a review of preclinical studies for human cancer prevention. Toxicol Appl Pharmacol 224: 274-283.

[35] Baur JA, Sinclair DA (2006) Therapeutic potential of resveratrol: the in vivo evidence. Nat Rev Drug Discov 5: 493-506.

[36] Jeandet P, Douillet-Breuil AC, Bessis R, Debord S, Sbaghi M, Adrian M (2002) Phytoalexins from the vitaceae: biosynthesis, phytoalexin gene expression in transgenic plants, antifungal activity and metabolism. J Agri Food Chem 50: 2731-2741.

[37] Adrian M, Jeandet P, Veneau J, Weston LA, Bessis R (1997)
Biological activity of resveratrol, a stilbenic compound from grapevines, against Botrytis cinerea, the causal agent for gray mold. J of Chem Ecology 23: 1689-1702.

[38] Soleas GJ, Diamandis EP, Goldberg DM (1997) Resveratrol: a molecule whose time has come? And gone?" Clinical Biochem 30: 91-113.

[39] Siemann EH, Creasy LL (1992) Concentration of the phytoalexin resveratrol in wine. Am $\mathrm{J}$ of Enology and Viticulture. 43: 49-52.

[40] Das DK (2006) Resveratrol in cardioprotection: a therapeutic promise of alternative medicine. Mol Interv. 6: 36-47.

[41] Dominique Bonnefont-Rousselot D (2016) Resveratrol and Cardiovascular Diseases. Nutrients 8: 250.

[42] Li H, Xia N, Förstermann U (2012) Cardiovascular effects and molecular targets of resveratrol. Nitric Oxide 26: 102-110.

[43] Jing YH, Chen KH, Yang SH, Kuo PC, Chen JK (2010) Resveratrol ameliorates vasculopathy in STZ-induced diabetic rats: role of AGE-RAGE signalling. Diabetes Metab Res Rev 26: 212222

[44] Das S, Lin HS, Ho PC, Ng KY (2008) The impact of aqueous solubility and dose on the pharmacokinetic profiles of resveratrol. Pharm Res 25: 2593-2600.

[45] Nunes T, Almeida L, Rocha JF, Falcão A, Fernandes-Lopes C, Loureiro AI, Wright L, Vaz-da-Silva M, Soares-da-Silva P. (2009) Pharmacokinetics of trans-resveratrol following repeated administration in healthy elderly and young subjects. J Clin Pharmacol 49: 1477-1482.

[46] Marier JF, Vachon P, Gritsas A, Zhang J, Moreau JP, Ducharme MP (2002) Metabolism and disposition of resveratrol in rats: extent of absorption, glucuronidation, and enterohepatic recirculation evidenced by a linked-rat model. J Pharmacol Exp Ther 302: 369-373. 